\title{
A PAISAGEM DOS GEÓGRAFOS RUSSOS: A EVOLUÇÃO DO OLHAR GEOGRÁFICO ENTRE O SÉCULO XIX E O XX
}

\author{
The landscape of the russian geographers: \\ the evolution of the geographical perspective between \\ the nineteenth and the twentieth centuries
}

\author{
Marina FROLOVA 1
}

\begin{abstract}
RESUMO
A Geografia russa desenvolveu-se entre os séculos XVIII e XX sob a influência de diversas correntes científicas e práticas sociais. A história da abordagem pitoresca na Geografia russa mostra provavelmente da maneira mais espetacular a evolução do olhar geográfico sobre o mundo. No início do século $\mathrm{XX}$, a paisagem representa uma categoria quase universal, largamente utilizada pelos geógrafos russos. No entanto, essa noção entrou na língua russa apenas no fim século XVIII através de dois termos existentes em outras línguas: Landschaft e paysage. Se essas palavras foram sinônimas durante dois séculos, nos anos 1930-1940 atribuiu-se à primeira o sentido científico e à segunda o sentido artístico e simbólico por excelência. Como as escolas da geografia russa contribuíram para a evolução da noção de paisagem? Por que se produz um divórcio entre os termos Landschaft e paysage? Qual papel utiliza a paisagem na geografia russa hoje? O autor procura compreender os paradoxos da evolução do olhar geográfico na Rússia do fim do século XIX e no século $X X$, analisando as transformações da abordagem pitoresca.
\end{abstract}

Palavras-chaves:

Concepção da paisagem; epistemologia; evolução; geografia; Rússia.

\begin{abstract}
From the eighteenth to the twentieth century, Russian geography developed under the influence of different scientific trends and social practices. The history of the concept of landscape reveals in a spectacular way the evolution of the geographical approach to the environment. By the beginning of the twentieth century, 'landscape' was viewed as a universal category, and was widely used by the Russian geographers. This term, however, did not appear in Russian geography until the end of the eighteenth century, with the adoption of two words of foreign origin: Landschaft and paysage. For two centuries, these words were synonyms, but by $1930-1940$, the term Landschaft had been restricted to a scientific meaning, at a time when the word paysage was beginning to be used to refer to scenery. How did the Russian geographical schools affect the evolution of the word landscape? What led to the divorce between the terms Landschaft and paysage? What is the role of these two words in contemporary Russian geography? The author attempts to explain the particularities of the development of Russian geography between the end of the nineteenth and the end of the twentieth century through the analysis of the evolution of the concept of landscape.
\end{abstract}

Key words:

Geography; landscape concept; epistemology; evolution; Russia.

1 É licenciada em Geografia, Ecologia e Paisagem pela Universidade Estatal de Moscou e doutora em Geografia e Ordenação do Território pela Universidade de Toulouse II, especializada na interpretação da evolução de paisagens. Publicou diversos trabalhos relacionados a esse tema e sobre a história da geografia Russa e trabalhou em diferentes equipes internacionais (Universidade Estatal de Moscou, Escola de Arquitetura e Paisagem de Bordeaux, Instituto de Geografia da Academia de Ciências da Rússia, Laboratório GEODE da Universidade de Toulouse II, Universidade de Jaén - Espanha, Universidade Autônoma Metropolitana do México). Na atualidade, é pesquisadora do programa Ramon e Cajal da Universidade de Granada, Instituto de Desenvolvimento Regional. 
FROLOVA, M. A paisagem dos geografos russos: a evolução do olhar geografico entre o século XIX e XX

\section{INTRODUÇÃO}

O nascimento da ciência da paisagem na Rússia data do fim do século XIX. Foi a época das primeiras reflexões sobre a paisagem como método verdadeiramente geográfico do estudo do meio. Vários fatores participaram na formação da ciência da paisagem na Rússia: a necessidade de inventar meios eficazes para estudar vastas extensões pouco habitadas; as tradições das grandes expedições; a participação ativa dos militares e engenheiros nas investigações geográficas; a inspiração dos naturalistas russos no século XIX pelas idéias da Natur Philosophie; sem esquecer as perturbações políticas e a influência da ideologia marxista no século XX. A história complexa da apropriação do seu território pelos Russos, ligada, ao mesmo tempo, aos fatores políticos, geográficos e culturais, conduziu à emergência de uma atitude muito específica dos cientistas russos para com a natureza. Com efeito, a geografia russa desenvolveu-se sob a forte pressão da necessidade de colonização de vastos espaços, próximos, como o Ural e o Cáucaso, ou remotos, como Sibéria. No apogeu dessa apropriação das "margens próximas", no fim do século XIX, uma nova concepção geográfica constitui-se, no centro da qual se encontra a noção de paisagem.

$\mathrm{O}$ início do século XX marca uma grande ruptura na visão da paisagem pelos geógrafos e naturalistas russos. Essa ruptura é precedida por mudanças importantes dentro da própria geografia. Durante o século XIX, a geografia aparecia junto de diversas práticas (as explorações militares, as experiências de viagem e descrições estatísticas) e afirma-se como disciplina universitária. ${ }^{2}$ Fruto da investigação de meios eficazes de gestão do seu imenso espaço e a criação rápida de mapas dos vastos territórios, a geografia russa, como na Alemanha, tenta substituir o estudo das relações funcionais pelos dados fisionômicos. (ROUGERIE, 1991)

Os cientistas russos, desenvolvendo a lógica de investigação geográfica proposta por A. V. Humboldt, continuam a refletir sobre a paisagem como objeto específico do estudo geográfico cuja função é englobar uma relação universal existente entre os diversos elementos do meio e a sua subordinação no espaço. É durante esse período que se estabelecem as bases da nova ciência geográfica que será chamada, no século XX, de o Landschaftovedenie ou ciência da paisagem. Emerge como resultado do esforço para reunir duas idéias: a da descontinuidade do meio, fruto da sua estrutura pluricomposta, e a da sua continuidade e a sua unidade no espaço e no tempo.
Para desenhar o objeto de estudo dessa ciência, a paisagem, os russos utilizaram a palavra alemã Landschaft. Apresentada como um grupo de objetos e de fenômenos que se repetem regularmente sobre a superfície terrestre, a paisagem será vinculada, ao mesmo tempo, aos fatos "visíveis", que surgem da experiência comum da observação - o ponto de partida das descrições geográficas tradicionais - e a apreensão dos fenômenos inacessiveis à intuição do homem como, por exemplo, a organização estruturada do espaço geográfico. Escondida por partes posteriores as formas apercebidas pelo olhar do observador, a essência objetiva da paisagem coloca-se progressivamente no centro da investigação geográfica. É assim que os geógrafos russos descobrem, entre o fim do século XIX e a primeira metade do século $X X$, os novos componentes da paisagem como, por exemplo, o solo. Esses componentes não fazem mais parte da antiga concepção da paisagem, ligada à visibilidade. Diferentemente da paisagem de Humboldt, a Landschaft dos geógrafos russos adquire cada vez mais os traços do modelo científico abstrato, que se afasta progressivamente da representação sensível da paisagem. A paisagem será objetivada cada vez mais, sobretudo pela influência da doutrina marxista que vai dominar na Rússia a partir de 1917.

No entanto, uma contradição reside no cerne da noção de paisagem, ao mesmo tempo objeto da realidade espacial e assunto da percepção, que vai provocar, no século XX, discussões contínuas entre os geógrafos sobre a sua definição, sobre a morfologia da sua estrutura e sobre os seus métodos de estudo. A história da abordagem pitoresca na geografia russa mostra provavelmente da maneira mais espetacular a evolução do olhar geográfico sobre o mundo. Já no início do século XX, a paisagem representa uma categoria quase universal, largamente utilizada pelos geógrafos. No entanto, essa noção entrou na língua russa apenas no fim do século XVIII, através de dois termos existentes em outras línguas: Landschaft e paysage. Essas palavras foram sinônimas durante dois séculos, nos anos 1930-1940 atribuiu-se à primeira o sentido científico e à segunda o sentido artístico e simbólico por excelência. $O$ divórcio entre esses conceitos era ainda mais fácil por serem palavras estrangeiras.

Como aparece o conceito de paisagem geográfica na Rússia? Como as grandes escolas da geografia russa contribuíram para a evolução da noção de paisagem? Há um divórcio entre os dois termos, que significaram a mesma coisa? Qual o papel da paisagem na geografia russa hoje? Para responder a essas perguntas, devemos começar pelo período de constituição das primeiras abordagens científicas da paisagem na Rússia (anos 1860-1917).

2 As cadeiras de geografia foram criadas nas universidades russas graças à oukase (decreto) de 23 de agosto de 1884. Anteriormente, eles não ensinaram a geografia física unicamente em cadeiras de Física, freqüentemente lecionavam também em Meteorologia. (grifo nosso) 
FROLOVA, M. A paisagem dos geografos russos: a evolução do olhar geografico entre o século XIX e XX

\section{EMERGÊNCIA DA CONCEPÇÃO CIENTÍFICA DA PAISAGEM}

Durante as últimas décadas do século $\mathrm{XIX}$, o estatuto da geografia e dos geógrafos que estudam a Rússia foi alterado profundamente. Os anos 1860-1890 tornam-se o tempo do desenvolvimento das investigações geográficas, que coincide com um período de importantes transformações econômicas e sociais na Rússia. Os anos 1860 são marcados na Rússia por grandes mudanças: em 1861, Alexandre II liberta os escravos, que representam ainda um terço da população campesina, e começa a realização de reformas na vida social. De um lado, os camponeses liberados têm necessidade de lotes de terreno. Do outro, a anexação do Cáucaso e dos países da Ásia Central oferece um campo imenso para a colonização. É por isso que essa época é marcada pela apropriação dos novos recursos e das novas terras e pela ativação das investigações ligadas à prática agrária. (VALEBNYİ, 1998)

Notamos que as reformas econômicas lançadas pelo governo não foram eficazes e são mal aceitas por certas camadas inteligentes e revolucionárias. A situação econômica da Rússia complica-se por desastres climáticos e más colheitas. Conseqüentemente, a partir dos anos 1860-1870, os geógrafos começam a desempenhar um papel importante (como anteriormente os geólogos, botânicos e militares) na investigação de meios para resolver os problemas econômicos do país e trazer à luz, de uma maneira científica, os seus vastos espaços ainda pouco estudados, em especial as estepes da Ucrânia e da Sibéria meridional, as regiões do Cáucaso e da Ásia Central. A Sociedade da Livre Economia propõe um programa de estudos exaustivos dos recursos naturais no sul da Rússia e a sua avaliação será realizada em 1880-1890 por numerosas missões científicas.

Paralelamente ao progresso da prática de exploração, a geografia russa evolui sob a influência de idéias novas vindas da Europa. A sistematização dos dados das várias expedições organizadas durante os anos precedentes e o novo ponto de vista sobre a realidade espacial provocam um progresso essencial nas investigações geográficas. A mudança do olhar geográfico torna-se aparente nos trabalhos de Piotr Petrovitch Semionov Tian-Chanski, que desenvolve na
Rússia as idéias da geografia comparada. Semionov apóia-se largamente sobre as concepções da geografia alemã, à qual dá muita importância: conhece Ritter pessoalmente e considera-o como o seu mestre, ao mesmo tempo em que continua a ser influenciado por Humboldt, cujas obras analisa com cuidado. Após ter traduzido a Geografia da Ásia de Ritter em russo (1856), Semionov enriquece essencialmente a concepção do seu "mestre" da ciência comparativa da Terra, o programa de estudos descritivos da natureza e das populações de diversos países nas suas relações. Diferentemente de Ritter, Semionov concebia a geografia como uma ciência prática, que pode servir às necessidades do homem. Contrariamente à escola de geografia fiscal de Ritter, a escola geográfica russa desenvolveu-se seguindo as tradições das Expedições Acadêmicas, com base num conhecimento prático da Terra ${ }^{3}$.

Ainda mais sensível, para o desenvolvimento da geografia russa, será a influência das escolas geográficas de Anoutchine e de Dokoutchaev, formadas nesse mesmo período. Essas escolas proporão métodos mais concretos de investigação e definirão a paisagem (com diversos títulos) como objeto integrador da geografia. A primeira escola forma-se na Sociedade Imperial dos Amantes das Ciências da Natureza, da Antropologia e da Etnologia de Moscou, fundada em 1863. O seu fundador Dmitri Nicolaïevitch Anoutchine altera progressivamente a orientação da geografia na Rússia para o estudo geomorfológico e cria uma escola dita das "regiões morfológicas" (районно-морфологическая школа). Ele afirma que os objetos específicos da geografia física são as esferas que envolvem a Terra e que se interpenetram. (ANOUTCHINE, 1912,1949) Conseqüentemente, propõe centrar o estudo geográfico sobre as leis físicas da evolução da superfície terrestre, da história da formação dos objetos e dos fenômenos geográficos. Formado ao mesmo tempo como zoólogo, antropólogo e geógrafo, é movido pelo fato de que cada ciência tem os seus objetos, fins e métodos particulares de estudo, assim insistiu na delimitação da geografia como ciência. Anoutchine recusa as investigações de caráter enciclopédico, efetuadas em outros lugares pelos geógrafos: a Rússia é relativamente bem explorada, não se trata mais da descoberta geográfica de novas terras. Em contrapartida, é necessário aprofundar o estudo dos aspectos especificamente geográficos das

3 O papel de P. P. Semionov no desenvolvimento da geografia russa da segunda metade do século XIX é sem dúvida importante. A legitimidade de uma denominação do grupo dos geógrafos reunidos por ele, a "escola geográfica de Semionov", é aceita na historiografia soviética (ABRAMOV, 1972), mas estes são contestados por Oliveira Orain (1996), que sublinha que Semionov não teve concepções realmente originais para a geografia, nem verdadeiros discípulos. Será necessário contudo observar que o funcionário de Estado, cientista e explorador exerce uma influência importante sobre os geógrafos russos e o grande público como autor das primeiras obras de vulgarização geográfica, consagradas à descrição sistemática do conjunto do país (A Rússia pitoresca, Rússia, A descrição completa da nossa pátria, etc.). 
FROLOVA, M. A paisagem dos geografos russos: a evolução do olhar geografico entre o século XIX e XX

regiões da Rússia. De acordo com ele, o estudo das diversas regiões do país deve ser mais especializado. Considera a geografia não como "conglomerado das ciências variadas da Terra", mas como uma ciência independente e sintética. (ABRAMOV, 1972)

Anoutchine utiliza muito o método da comparação geográfica, emprestada das concepções da geografia alemã, dando, ao mesmo tempo, uma atenção específica à história da formação dos objetos e dos fenômenos naturais, e aposta nos seus relatórios de causalidade. Notamos que a partir de 1884 Anoutchine é o diretor da primeira cadeira de Geografia e de Etnografia, fundada em 1884, que está unida à Faculdade de História e Filologia da Universidade de Moscou ${ }^{4}$, que reforça a influência das suas idéias sobre a geografia russa ${ }^{5}$. A terceira corrente geográfica russa formada nesse mesmo período é a do mineralogista de formação, professor da Universidade de Moscou, Vassiliy Vassilievitch Dokoutchaev. As concepções de Dokoutchaev, que lançou as bases da ciência da paisagem e uma nova escola geográfica na Rússia, se apóiam sobre duas fontes científicas. Em primeiro lugar, Dokoutchaev parte, nas suas reflexões, da idéia filosófica espalhada no século XIX de que a natureza é única, contínua e indivisível. Do outro, a análise da prática agrária que o conduz a propor questões sobre o papel do solo nos sistemas territoriais, que considera pela primeira vez como corpus natural específico.

Como fato, observa Vetchaslav Valebnyi (1998), o nascimento da nova abordagem da realidade geográfica é mesmo intimamente ligado ao caráter dos problemas, que Dokoutchaev procurou solucionar. Após ter retornado das suas expedições nas estepes do sul da Rússia, enviado para compreender as razões da regressão da floresta e o empobrecimento dos solos nas estepes do sul, publica, em 1892, uma obra intitulada Nossas estepes outrora e hoje. Apoiando-se sobre os fenômenos observados nas estepes, propõe uma abordagem revolucionária que examina o solo como um objeto distinto que se desenvolve num processo de interação entre as componentes abióticas e bióticas de um complexo espacial, mas também considerando o homem ${ }^{6}$. Além disso, coloca a questão da abordagem histórica dos solos e as zonas geográficas em geral. Para Dokoutchaev, o solo é, ao mesmo tempo, um corpo natural e histórico, cada zona geográfica representa igualmente a região genética, ou seja, formado durante um processo histórico; logo, é necessário estudá-lo do ponto de vista da variabilidade da natureza no tempo e no espaço. Essa nova abordagem fortaleceu as interações entre a vegetação, o relevo, a geologia, o clima e a atividade humana e orientou a geografia russa para a análise sintética da paisagem e a história da sua formação. ${ }^{7}$

Convém ressaltar o fato de Dokoutchaev não empregar o termo Landschaft para materializar esse relatório (NIKOLAEV, 1996). No entanto, as suas idéias foram integradas, no século $X X$, não somente nos trabalhos dos seus discípulos (G. N. Vysïotskis, G. F. Morozov, G. I. Tanfiliev e V. I. Vernadski), mas também de qualquer investigação físico-geográfica efetuada na Rússia.

\section{ASCENSÃO DA CIÊNCIA DA PAISAGEM}

\section{NASCIMENTO DA LANDSCHAFTOVEDENIE}

Já durante os anos 1890-1920 aparecem vários trabalhos geográficos que refletem sobre a noção de paisagem. Os seus autores apóiam-se sobre observações feitas nas regiões pouco habitadas das latitudes médias. Em 1895, A. N. Krasnov propõe estudar as

4 Apesar da sua atribuição à Faculdade de História e de Filologia, essa cadeira ocupa-se dos problemas corretamente geográficos e a explicação dos fenômenos físicos do espaço terrestre em especial. É por isso que, a partir de 1888, essa cadeira será transferida ao Departamento das Ciências da Natureza da Faculdade de Física e de Matemática (KRASNOPOLSKI, 1995).

5 Constatam, no entanto, na seqüência de Oliveira Orain (1996), que Anoutchine não deixou de lado o modelo epistemológico, como o fizeram os fundadores das outras escolas geográficas. O seu olhar sobre a geografia, ainda maleável como disciplina, reside contraditório: apesar dos seus ensaios para redefinir os objetos da geografia, duvida da sua independência como disciplina. Testemunham os fatos expostos por Nikolaov Dronine no seu livro Evolução da concepção de paisagem na geografia russa e soviética (1999): o autor cita alguns contemporâneos de Anoutchine, que afirmam que as obras deste grande geógrafo tinham antes um caráter analítico e crítico que construtivo ou doutrinário. Do mesmo modo, O. Orain (1996) escreve que Anoutchine aparece-lhe antes como "letrado, um homem de gabinete, dotado de um notável espírito de síntese e de divulgação", que como um fundador verdadeiro de uma escola geográfica.

6 Anteriormente o solo era tratado apenas como uma formação geológica superficial.

7 Expõe essa concepção, pela primeira vez, no seu artigo "Zonas Pedológicas Verticais e Horizontais do Cáucaso" (1898, 1948, p. 11), estudava geralmente os corpos separados - os minerais, balanços, plantas e animais - e os fenômenos ou os elementos separados - 0 fogo (vulcanismo), as águas, a terra, o ar, mas nunca estudava-se a relação genética, eterna e sempre regular que existe entre as forças, os corpus e os fenômenos da natureza, entre as naturezas mortas e vivas, entre os reinos vegetais, animais e minerais, de um lado, e do outro o homem. No entanto, são esses relatórios, essas interdependências regulares, que representam a essência da compreensão da natureza, o núcleo da verdadeira filosofia - o encanto superior das ciências da natureza. 
"espécies" e os "tipos" dos "complexos geográficos" dos quais a formação resulta das combinações específicas dos climas, dos relevos, dos processos geodinâmicos e das vegetações (KRASNOV, 1895, p. 5). Em 1904, G. N. Vyssotski, discípulo de Dokoutchaev, faz as suas investigações em estepes e propõe como objeto de investigações físico-geográficas o ecótopo. Do mesmo modo, em 1908, A. A. Borzov desenvolve a concepção do complexo natural territorial. Na sua obra Quadros geográficos da Rússia (BORZOV, 1908), na qual se refere aos trabalhos de E. Reclus, F. Ratzel e A. N. Krasnov, afirma que a geografia é uma ciência das paisagens, que são, ao mesmo tempo, conjuntos de elementos físicos e "quadros" harmoniosos da natureza. Por último, um discípulo de Anoutchine, Lev Semionovitch Berg, propõe, no seu artigo "Ensaio da divisão da Sibéria e do Turcomenistão em regiões pitorescas e morfológicas" (1913), a primeira definição científica da paisagem. Na sua obra posterior, Objeto e problemas da geografia (1915), mostra a paisagem como um objeto integrador da geografia, que marca a sua especificidade em relação às outras disciplinas e representa a finalidade dos seus estudos. Desenvolvendo as idéias de Dokoutchaev e a concepção cronológica de A. Hettner ${ }^{8}$, propõe como objeto de estudo geográfico as unidades espaciais de escalas diferentes (da paisagem à zona geográfica). Assim a geografia, como o afirma L. S. Berg, tem o seu objeto (a paisagem) e o seu método (a regionalização).

Escolhendo para a sua concepção a palavra de origem alemã Landschaft, Berg define a paisagem como uma região na qual as particularidades do relevo, do clima, das águas, do solo, da vegetação e da atividade antrópica são organizadas num conjunto geográfico harmonioso, de acordo com um modo que pode repetirse dentro de uma mesma zona geográfica (Figura 1). Essa nova interpretação da paisagem possui três características importantes. Primeiramente, a paisagem é considerada como uma unidade homogênea. Em segundo lugar, a identidade das paisagens diferentes revela-se na semelhança das suas composições. Por último, a paisagem de Berg engloba os elementos do ecossistema e a atividade do homem.

Basicamente, se podem ver duas abordagens possíveis da realidade geográfica. Se a paisagem é uma unidade espacial homogênea que "se repete de maneira típica" dentro de uma mesma zona geográfica, pode ser estudada como um complexo territorial original, mas também como um tipo de região geográfica

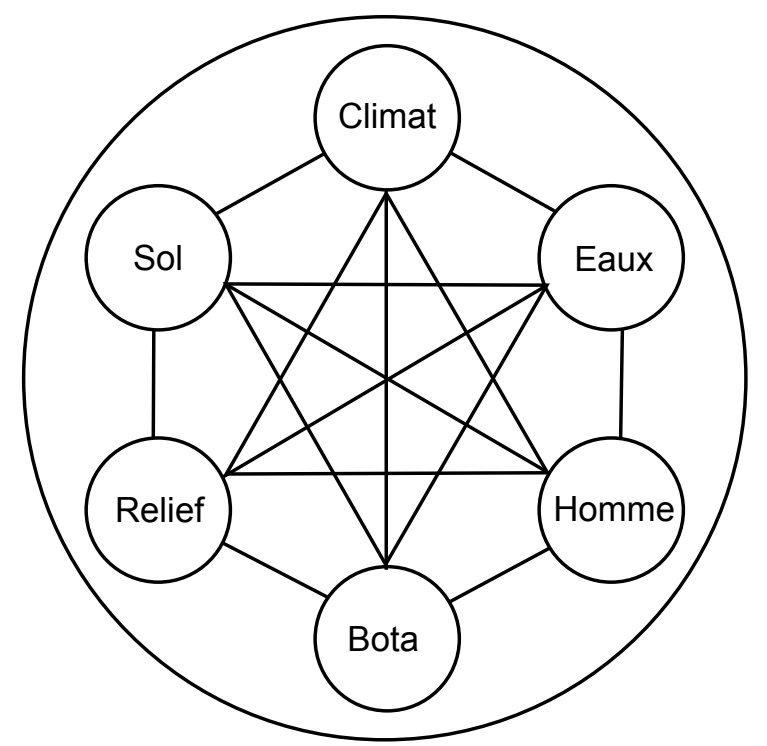

FIGURA 1 - PRIMEIRO MODELO DE PAISAGEM DE L. S. BERG

de uma escala precisa. Trata-se, com efeito, de duas visões opostas do mesmo objeto. De um lado, essa concepção confirma a existência das unidades naturais subordinadas uma a outra e vinculadas a um território preciso, fixando assim a descontinuidade espacial da natureza. Do outro, as afirmações que se repetem sobre a superfície terrestre nos limites de certas zonas geográficas é ligada à idéia da continuidade. Essa oposição, ainda não muito articulada, vai provocar o aparecimento, dentro da ciência da paisagem, de pontos de vista antagônicos sobre a paisagem. A definição "pitoresca" de Berg coloca também outros problemas: qual lugar é necessário atribuir ao homem na paisagem? Durante todo o século XX os geógrafos da paisagem vão hesitar entre uma abordagem que totaliza, segundo a qual o homem faz parte da paisagem que transforma, e uma abordagem dualista, segundo a qual o homem representa uma força externa à paisagem. Formado ele mesmo na escola de Anoutchine, Berg considerava o homem como parte integrante da paisagem, no início da sua carreira científica, mas alterou seguidamente $o$ seu ponto de vista original. (Figura 2)

8 De acordo com N. M. Dronine (1999), as obras conceituais de A. Hettner, traduzidas e publicadas em russo durante as primeiras décadas século XX, desempenharam um papel importante no desenvolvimento dos métodos de estudos de paisagem na Rússia. 


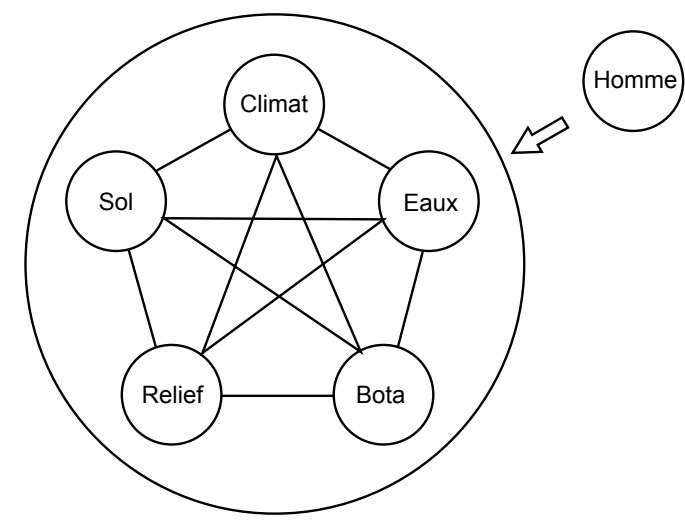

FIGURA 2 - MODELO DE PAISAGEM QUE SE AFIRMA NOS ANOS DE 1940

\section{PROBLEMAS EPISTEMOLÓGICOS DA CIÊNCIA DA PAISAGEM}

Desde a invenção da paisagem científica, as perguntas sobre sua continuidade ou sua descontinuidade e o dualismo ou o globalismo da abordagem da paisagem serão tratados de maneiras diferentes. Com efeito, pontos de vista opostos vão coexistir na Rússia durante todo o século XX e servir para a resolução dos diversos problemas. Serão dados aqui alguns exemplos.

\section{Dinâmica e funcionamento da paisagem}

Para compreender os processos que vinculam os elementos do meio entre si, era indispensável adaptar a visão da paisagem como corpo contínuo e integrador no espaço e no tempo. Já no início do século $X X$, se lançam as bases de uma nova abordagem do espaço geográfico, fundado sobre a idéia da continuidade dos processos que têm lugar no meio. Um impulso profundo ao desenvolvimento dessa abordagem foi dado por Vladimir Ivanovitch Vernadski (1863-1945). Baseandose na lei periódica dos elementos químicos de Dmitri Mendéléiév e na idéia de fluxos de matéria, passou dos problemas da mineralogia descritiva à criação de uma ciência nova, a geoquímica. A geoquímica esforça-se em aprofundar os problemas teóricos, coloca a origem da distribuição dos elementos químicos e das suas combinações nas diversas esferas do globo. Em 1906 Vernadski publica a sua obra de concepção científica do mundo, na qual propõe a noção nova de biosfera.
O exemplo de Dokoutchaev sublinha a importância das interações entre os fenômenos da vida (biosfera) e a matéria abiótica (atmosfera, hidrosfera, litosfera) que se realizam por fluxos de matéria e de energia. Subseqüentemente, colocando-se a questão do papel da energia do Sol nos processos terrestres, introduz, nas ciências naturalistas, a idéia de um estudo das trocas de matéria e de energia.

Destarte, nos anos de 1920, Boris Borissovitch Polinov adota as idéias de Vernadski sobre a interação dos elementos do meio à escala da paisagem. Reconhece a existência de uma esfera intermediária entre os balanços e a matéria viva - "cortiça da alteração", que funciona de acordo com as regras específicas da troca de energia e de matéria. Seguidamente, propõe uma noção de "paisagem geoquímica" - complexo natural territorial cujos componentes são unidos geneticamente pela migração dos elementos químicos. Pode-se, por conseguinte, assinalar a emergência de um novo olhar sobre a paisagem. Não composto de elementos estáticos fixados visualmente: os componentes da paisagem são vinculados por processos, que é mesmo a expressão da continuidade do meio. A paisagem torna-se ao mesmo tempo um processo natural e a metáfora de uma interdependência entre os elementos da natureza.

\section{Morfologia da paisagem}

Durante esse mesmo período, os geógrafos russos colocam questões novas relativas à estrutura dos complexos territoriais e às paisagens. Em 1926 Leontyï Grigorievitch Ramienski, em sua obra Introdução ao estudo integrativo dos solos e da vegetação, formula a hipótese da descontinuidade natural, intrínseca, da vegetação e a existência de uma fronteira nítida entre cenoses, devida à influência das culturas e a alteração descontínua de outros fatores. Assim, a descontinuidade da vegetação não aparece mais como um fenômeno inerente a uma dinâmica limpa da vegetação, mas como o resultado de circunstâncias ambientais. Conseqüentemente, desenvolvendo ao mesmo tempo idéia da unidade e a descontinuidade simultânea da natureza, colocada no centro da noção de paisagem, Ramenski propõe uma reflexão sobre a divisão da paisagem em partes. Doravante a paisagem não mais será considerada como um complexo territorial absolutamente homogêneo: é apresentada como a unidade que comporta sistemas de ordem menor, como ourotchié 9 , miestnost, fácies ${ }^{10}$, etc., vinculados por fluxos laterais de matéria 
e de energia. Mas a delimitação desses complexos territoriais coloca verdadeiros problemas, porque as fronteiras entre eles são suaves e não existem critérios comuns para o realce dos fatores ativos responsáveis pela sua formação, exceto, talvez, os fatores zonais e azonais. (RETEYUM, 1977)

\section{Dualismo ou aproximação totalizante?}

Ao mesmo tempo, os geógrafos russos tentam resolver outro problema de ordem epistemológica: o homem representa uma força comparável à da natureza e, por conseguinte, é necessário considerar os elementos naturais e "antropogeográficos" como um conjunto único? Ou, pelo contrário, é necessário opor o homem ao ambiente natural, que determina a organização do espaço pelas sociedades? As primeiras concepções dos geógrafos russos (escolas de Anoutchine e de Dokoutchaev) continuavam a ser ainda permeáveis a qualquer um que estava atrelado na cultura e na história da relação homem-natureza. É o caso de Dokoutchaev, ele mesmo, que fala nos seus trabalhos de uma "interdependência genética, que existe desde sempre entre a natureza e o seu mestre ilusório, o homem, sua vida material e espiritual" que se manifesta nas zonas históricas e naturais. (1899, p. 19)

No fim do século XIX, os geógrafos continuam muito atentos ao papel do homem na formação da paisagem. No entanto, não compartilham o mesmo ponto de vista sobre o caráter das relações entre o homem e o meio. A abordagem de Dokoutchaev que a totaliza opõe-se ao olhar dualista surgido entre os geógrafos que participam ativamente nos estudos consagrados com os efeitos da colonização russa sobre os novos espaços. Assim, o climatólogo e geógrafo Alexandre Voïeïkov se dedica muito tempo às regiões caucasianas anexadas pela Rússia e publica o seu artigo a "Influência do homem sobre a Terra" em 1894 (a tradução francesa será publicada nos Anais de Geografia em 1901), no qual analisa os aspectos diversos da antropização do meio natural. Do mesmo modo, o geógrafo e botânico Andrei Krasnov explica os primeiros malogros da colonização do Cáucaso subtropical, pela ausência de estudos sobre as relações vernaculares entre os povos locais e o seu meio.
Ao mesmo tempo, aparecem concepções globalizantes ainda mais radicais que aquelas de Dokoutchaev e Berg nos anos 1910-1930; por exemplo, a de Vladimir Vernadski, de acordo com a qual o homem desempenha um papel tão importante nos seus processos de trocas energéticas e biogeoquímicas que seria necessário considerá-lo como uma força equivalente às forças geológicas e geoquímicas. Nos anos 19301940, desenvolvem a teoria da noosfera, a esfera dos conhecimentos, da razão, da transformação do meio pela civilização humana, que existe no mesmo plano que a biosfera, a litosfera, etc.

\section{NOVA IDEOLOGIA: ENTRE “NATUROCENTRISMO” E UTILITARISMO}

O traço mais importante das representações geográficas da paisagem das primeiras décadas do século XX é a sua extrema diversidade: os modelos naturalistas coexistem com concepções que englobam a realidade natural e humana, as abordagens "objetivistas" com as que se baseiam na apreensão da paisagem como aspecto visível do território, as concepções do descontinuismo espacial e temporal da natureza, as abordagens geográficas que debatem sobre a hipótese da continuidade dos processos naturais no espaço e no tempo. Essa diversidade de abordagens vai desaparecer progressivamente da geografia sob a influência de uma nova ideologia e das mudanças sociais e econômicas na Rússia.

Nos anos 1930-1940, a ciência da paisagem afirma-se definitivamente como um ramo da geografia da mesma ordem que a geomorfologia, a biogeografia, a pedologia, etc. ${ }^{11}$ Apresenta-se já como uma ciência com os seus próprios objetos, mas os seus métodos de análise continuam a ser ainda demasiado descritivos, o que não corresponde mais ao espírito da época dos grandes pensadores socialistas e das "grandes transformações stalinienses da natureza".

A transição da sociedade russa do capitalismo ao socialismo provoca mudanças importantes nas ciências. A partir de 1917, com a Revolução de Outubro, os decretos do Estado soviético levam à nacionalização da terra, dos subsolos, das águas e das florestas e alteram

11 O Landschaftovedenie institucionaliza-se primeiro na Universidade de Moscou, onde A. Borzov a espalha, em 1938, na cadeira de geografia física da URSS, que é oficialmente aberta dessa 1939. Todos os trabalhos dessa nova cadeira terão por base, até ao fim século XX, a doutrina da paisagem (Landschaft). Ver, por exemplo, a obra consagrada no jubileu desse organismo universitário, publicada em 1999, que leva o nome emblemático Escola da Paisagem da Universidade de Moscou: tradições, realizações, perspectivas. (DIAKONOV; MAMAOV, 1999) 
FROLOVA, M. A paisagem dos geografos russos: a evolução do olhar geografico entre o século XIX e XX

radicalmente a sociedade russa e as suas relações com o meio. Essas mudanças acentuam as tendências já existentes no desenvolvimento da geografia da paisagem na Rússia, da qual a mais importante era o aspecto utilitário das investigações geográficas, e a sua relação direta com a prática. Ainda mais direta será essa relação na época de Stalin: doravante os geógrafos devem dar uma caução científica aos planos soviéticos de transformação da natureza. A finalidade de qualquer estudo geográfico nessa época é a mudança racional do meio geográfico em conformidade com os objetivos da construção socialista.

Mudanças importantes desenrolam-se igualmente sobre um plano ideológico. De um lado, a concepção materialista marxista, segundo a qual a base de qualquer conhecimento descansa na matéria - a realidade objetiva que se figura pelas nossas sensações -, haja vista que os geógrafos soviéticos aceitam como uma verdade absoluta a doutrina que afirma que as nossas sensações são meios eficazes para conhecer o mundo na sua objetividade. Do outro, introduziu-se, em toda a análise geográfica, a teoria marxista da luta das classes e a evolução das sociedades, segundo a qual um elemento indispensável do estudo histórico-geográfico é a lei da mudança das formações sociais (sociedade primitiva, feudal, capitalista, socialista). Cada uma entre elas deve corresponder, de acordo com essa doutrina, a um tipo específico da interdependência entre os homens e o meio. Recusando qualquer análise social, os geógrafos soviéticos denunciam a geografia "burguesa" de tipo clássico ${ }^{12}$ e declaram que são os resultados práticos que se exige dos trabalhos científicos que favorecem o desenvolvimento e o progresso da geografia. (GUERASSIMOV, 1956)

O novo olhar sobre a paisagem necessita métodos novos para a sua análise: são os modelos qualitativos e quantitativos que, de acordo com o pensamento geográfico soviético, podem permitir o controle do meio geográfico. Doravante as qualidades de uma paisagem podem ser representadas em termos de pesos, volume, índices, energia, migração dos elementos químicos, etc. Os cientistas, tentados pela investigação da objetividade na organização da paisagem, hesitam sobre a noção de paisagem de qualquer ordem sentimental e subjetiva. Essa tentativa será traduzida na Rússia por uma cisão semântica entre os termos paysage e Landschaft.

A abordagem quantitativa vai afirmar-se bastante rapidamente na geografia russa. Em 1931, o acadêmico A. A. Grigoriev, no seu artigo "Estudo físico-geográfico da URSS" (1931, citado por ABRAMOV, 1972), escreve que o método descritivo e explicativo não pode mais conservar a sua importância em geografia. Como conseqüência da valorização dos novos territórios, da introdução de novas culturas, da intensificação da agricultura, da construção industrial e das estradas em condições diferentes das habituais, é necessário pôr ao centro das investigações geográficas a análise dos processos complexos que determinam o dinamismo do meio natural. Grigoriev coloca no centro dos estudos geográficos a esfera geográfica, ou geosfera, que é composta por massas aéreas, águas e uma base litológica. Os seus componentes sofrem a influência da energia do Sol, que provoca a sua transformação e o aparecimento dos solos, dos vegetais e dos animais, considerados como processo físico-geográfico único ${ }^{13}$, cuja paisagem é uma expressão. A. A. Grigoriev sublinha que é impossível estudar a fisionomia da paisagem sem analisar o seu conteúdo material, que pode ser exprimido em fórmulas e equações. Além disso, precisa que o estado contemporâneo do meio e os seus elementos seja um produto da sua longa história. Assim, de acordo com o pensamento de Grigoriev, é impossível apreender o desenrolar dos processos geográficos no espaço sem compreender a dinâmica temporal do meio. Se a dinâmica espacial pode ser apreendida pela análise e pela síntese atenta dos materiais das expedições, os geógrafos deverão, para aproximar a dinâmica temporal, desenvolver uma nova abordagem do estudo do meio: uma investigação periódica ou permanente sobre estações geográficas especiais.

12 A influência do novo regime político tem-se referido sobretudo, e em primeiro, ao domínio específico da geografia que estudava a relação das sociedades e os seus meios e a distribuição espacial dos fatos humanos. Com efeito, muito rapidamente a geografia na Rússia divide-se em duas grandes partes cada vez mais separadas uma da outra: geografia física e geografia econômica. A segunda particularmente será desfavorecida pelo regime comunista, dado que a interpretação do papel e os fatores de desenvolvimento da sociedade será doravante um negócio ideológico. O elemento antropogeográfico desaparece das obras geográficas já em 1930. Como o escrito que celebra o geógrafoeconomista N.N. Baranski (1946, p.12), "após ter matado a antiga 'antropogeografia' ele não criou nada em troca; um capítulo relativo à população, que incorporava anteriormente os dados não somente da população e o povoamento, a sua distribuição e localização, mas também suas tradições, a sua cultura, hoje tem desaparecido completamente sem estar sendo unida aos estudos sobre a natureza (geografia física), nem sobre a economia (geografia econômica)." Esqueceu-se o homem.

13 N. M. Dronine mostrou que essa idéia é organicamente ligada à introdução na geografia soviética da teoria do materialismo dialético relativa às formas do movimento da matéria (DRONINE, 1999). Com efeito, as idéias de Grigoriev derivam da tese de F. Engels, segundo a qual são essas formas que são os objetos de estudo das ciências fundamentais. 
FROLOVA, M. A paisagem dos geografos russos: a evolução do olhar geografico entre o século XIX e XX

Continuando esse caminho, outro geógrafo soviético, D. L. Armand, afirmou em 1949 que o mapa não pode mais ser um objetivo principal da investigação geográfica. Deve ser completada por um gráfico ou um quadro, que representa o dinamismo temporal do fator geográfico estudado. Armand continua:

Os resultados de observações são apenas "matérias primárias" da investigação geográfica. São generalizados sobre um mapa, sobre os diagramas de balança e sobre as curvas que mostram o desenrolar dos processos no tempo. Assim, os mapas que figuram a distribuição espacial dos fenômenos geográficos são apenas um semiproduto da investigação. Para terminar a investigação e poder explicar cientificamente os processos que têm lugar na geosfera, é necessário tratar matematicamente os dados obtidos. (1949, p. 93-94)

O triunfo da nova concepção de investigação geográfica, a serviço dos objetivos utilitários, terá seu auge nos anos de 1960. São desse período os autores da obra coletiva A geografia soviética. Os resultados e os problemas (1960) exprimem os novos princípios da geografia:

A geografia moderna não é mais a ciência essencialmente descritiva de outrora, que tinha por objeto principal de estudo as terras e os países novos. É uma ciência de vocação transformadora, tendo por assunto principal as terras e os países por muito tempo conhecidos e postos em valor pelo homem, caracterizado por uma natureza profundamente perturbada, uma população densa, uma economia diversificada e evoluída. A geografia moderna não tem mais por objetivo essencial trazer em sua discussão a valorização das terras e riquezas naturais novas, mas deve oferecer uma base científica completa imensa ao trabalho da humanidade consagrada à exploração variada e sempre mais intensa dos recursos naturais conhecidos, à transformação da natureza e à economia das regiões e países já postos em valor. (citado por GUÉRASSIMOV, 1975, p. 13-14)

No entanto, as novas abordagens são dificilmente adaptáveis a uma concepção que totaliza a paisagem, proposta durante a primeira metade do século $X X$. Os acervos conceituais e as metodologias elaboradas em matéria de paisagem não correspondem mais a essas novas esferas. Como o sublinha o acadêmico Innokentiï Petrovitch Guérassimov em 1966, a ciência da paisagem "não resolveu os seus problemas metodológicos ligados à investigação e à elaboração dos métodos objetivos e precisos de divulgação e descrição científica dos seus objetos de investigação" (GUÉRASSIMOV, 1966, p. 389-403). Com efeito, a noção de paisagem não pôde dar uma chave explicativa, sintetizando a grande quantidade dos dados experimentais. Reside contraditória e contestada pelos geógrafos de escolas diferentes.

\section{TEORIA DO GEOSISTEMA}

É nesse período que aparece uma nova concepção que visa resolver esses problemas metodológicos, que se apóia sobre a teoria sistêmica. A doutrina dos geosistemas, proposta nos anos 1960-1970 por Sotchava, teve por base uma idéia de rota absoluta entre todos os "componentes" da paisagem que, devido à sua interação, Ihe dão um sentido. Sotchava define o geosistema como um sistema natural, de nível local, regional ou global, no qual o substrato mineral, o solo, as comunidades de seres vivos, a água e as massas de ar, particulares às diversas subdivisões da superfície terrestre, são interconectados por trocas de matéria e de energia, em só um conjunto (ROUGERIE; BEROUTCHACHVILI, 1991, p. 59). Ela funciona de acordo com as leis gerais da termodinâmica e da geoquímica. Emprestando as idéias da teoria sistêmica, a ciência da paisagem esforça-se por clarear os problemas da descontinuidade intrínseca da paisagem: os geosistemas são concebidos como polisistemas de compartimentos integrados. Os geosistemas são inseridos em cadeias que são sucessões de compartimentos e elementos em trânsito. Esse olhar que parcializa e reduz progressivamente o campo da paisagem em um único aspecto do sistema material geoquímico e geofísico.

Daqui em diante, todas as variações das descrições das paisagens pelos geógrafos soviéticos baseiam-se, sobretudo, no caráter dos conjuntos de elementos naturais, na sua distribuição e na história da sua formação, sua hierarquia e sua morfologia. No fundo, o que interessa mais aos geógrafos da paisagem a partir dos anos 1960-1970 são as dinâmicas espaciais e temporais das paisagens formalizadas e $o$ seu funcionamento. É nesse período que aparece um novo tipo de investigação pitoresca. Não se tem mais necessidade de percorrer o espaço para conhecê-lo: daqui em diante a investigação "estacionária", que consiste em análises repetitivas do dinamismo das unidades territoriais ou associações vegetais durante um período longo a partir de uma estação geográfica permanente, é utilizada cada vez mais pelos geógrafos de paisagem. As investigações passarão a ser feitas em estações experimentais instaladas distante das zonas de habitações (Sibéria, Extremo Oriente, Cáucaso, etc.). Aparece igualmente outro tipo de investigação, dita "semi-estacionária" (Sotchava), que consiste no estudo 
FROLOVA, M. A paisagem dos geografos russos: a evolução do olhar geografico entre o século XIX e XX

do território por cortes pitorescos repetidos periodicamente, a partir dos quais se operam generalizações espaciais e temporais. Convém sublinhar que todos os métodos foram concebidos para regiões pouco habitadas e foi suposto a priori que as paisagens estudadas eram exclusivamente "naturais".

\section{PAISAGEM CULTURAL OU ANTRÓPICA}

No entanto, seria injusto afirmar que a influência do homem não interessou os geógrafos soviéticos. O interesse manifestado nos anos 1970 pela influência antrópica sobre a paisagem não é novo. No fundo, a evolução dos olhares geográficos sobre o papel do homem no meio continua a ser sempre ligada ao mesmo problema da escolha entre globalismo e dualismo no estudo da paisagem. As primeiras reflexões metodológicas que consideram o homem e o ambiente como um conjunto único, do qual a expressão material é a paisagem, datam, como já ilustrado, da época de Dokoutchaev. Progressivamente, essa visão será substituída por um olhar dualista. O aparecimento, nos anos 1930, da expressão paisagem cultural (Berg, Neustroïev) é um sinal paradoxal pelo fato da noção de Landschaft perder a sua dimensão cultural. Primeiro essa noção é antes ligada às paisagens agrárias, cujos estudos conhecem ao longo dos anos 1920-1930 um verdadeiro desenvolvimento. Mas durante a década 1940-1950, a visão da paisagem cultural se altera essencialmente. Assim, o economista-geógrafo Oouriï G. Saouchkine entende pela noção de paisagem cultural "qualquer paisagem natural, onde as relações entre os elementos do meio natural são alteradas pela atividade do homem" (SAOUCHKINE, 1946, p. 97). Curiosamente, essa noção desaparecerá durante duas décadas do vocabulário geográfico soviético.

O elemento cultural retornou na concepção da paisagem apenas nos anos 1970, quando as ciências soviéticas do Landschaft voltaram-se outra vez para o papel do homem no processo de evolução da paisagem, mas em outro nível. Esse novo questionamento é fruto dos estudos sobre os efeitos das transformações voluntariosas da natureza. A otimização do ambiente torna-se um problema que interessa cada vez mais os geógrafos soviéticos. Começam a falar de um ambiente "ótimo" para o homem, há muito tempo considerado o meio que satisfaz apenas às suas necessidades fisiológicas, no novo contexto. Excede-se o quadro meramente ecológico e sublinha-se que a verdadeira paisagem cultural deve ser não somente "produtiva" e "sã", mas também bonita (ARMAND, 1968). Contudo, falando de paisagem cultural, os geógrafos estudam primeiro e, sobretudo, as paisagens naturais transformadas, evocando raramente as paisagens criadas pelo homem, como, por exemplo, os jardins e as cidades. Nessa abordagem, a análise do papel do homem, ou das sociedades continua a ser sempre substituída por uma análise de fatores de transformação dos elementos naturais. As paisagens culturais desenvolvem-se, de acordo com os geógrafos soviéticos, de acordo com as leis da natureza. A história cultural e social é apenas um fundo secundário.

Nesse contexto, a paisagem cultural define-se como uma paisagem antrópica, natureza racionalmente transformada pelo homem. O funcionamento dessa paisagem pode e deve ser dirigido pelo homem (ISATCHENKO, 1976) para fins da eficácia econômica máxima e da melhoria do ambiente.

\section{CONCLUSÃO}

É necessário esperar o fim dos anos 1980, a época da liberação da ciência russa de certas doutrinas marxistas, de modo que a relação entre a sociedade e a paisagem não seja mais pensada na Rússia apenas sob o ângulo utilitário e ideológico. A paisagem vai reencontrar outra vez a sua dimensão cultural. Curiosamente, as novas tendências em geografia guardarão ainda o aspecto cumulativo e utilitário da análise pitoresca. Os novos trabalhos russos consagrados à percepção das paisagens apresentam-se como ensaios de avaliação das qualidades estéticas das paisagens "utilizadas" para o lazer (que os geógrafos russos chamam de "Landschaften recreativos". Propõem sistemas variados de índices qualitativos e quantitativos, evocados para objetivar a análise do processo subjetivo da percepção. É apenas no fim dos anos 1990 que aparecem novas obras que tratam a paisagem como uma unidade funcional da investigação geográfica, mas também como uma noção que se encontra no centro da relação entre a natureza e a cultura, o ambiente e a sociedade. ${ }^{14}$ Testemunha igualmente a publicação dos resumos das comunicações do Congresso da Paisagem da Rússia em 1997. Embora a maioria dos textos seja escrita de acordo com as mesmas tradições da abordagem utilita-

14 Ver, por exemplo, as obras de V. L. Kaganski e B. B. Rodoman (1995), V. N. Kaloutskov et al. (1998) e V. V. Valebnyi et al. (1998). Constate que dois deles cortejam as intervenções feitas desde 1995 no âmbito do seminário pluridisciplinar de paisagem cultural, organizado pela cadeira de Geografia Física e a Paisagem da Universidade do Estado de Lomonosov, Moscou. 
FROLOVA, M. A paisagem dos geografos russos: a evolução do olhar geografico entre o século XIX e XX

rista e funcional da paisagem, um dos capítulos dessa obra é consagrado aos problemas da percepção e das representações da paisagem.

Assim, no limiar do século XIX a paisagem russa retoma um aspecto cultural. A objetividade "científica" da sua concepção geográfica é entregue em questão. Certos geógrafos russos pensam que é tempo de recusar esse termo porque ele é leve e distante de ser cientista. Os outros crêem que a paisagem única pode servir de

\section{REFERÊNCIAS}

ABRAMOV, L. S. Descriptions naturalistes de notre pays: Développement de l'approche physico-géographique. АБРАМОВ Л. С. Описания природы нашей страны: Развитие фризико-географрических характеристик: Moscou: Myisl, 1972. $277 \mathrm{p}$.

ANOUTCHINE, D. N. De l'enseignement de la géographie et des questions liées à l'enseignement (1912) In: Recueil de. анучин дмитрий Н. "О преподавании географии и вопросах с ними связанных" в Избранные географические работы). Moscou: OGIZ, 1949. p. 99-110.

ARMAND, D. L. Relations fonctionnelles et corrélatives en géographie physique: Mémoires de la Société géographique de I'URSS APMAНД Д. Л. “Функциональные и коррелятивные отношения в фризической географии "в Известия Всес. Геогр. о-ва. v. 81, n. 1, p. 81-94, 1949.

BARANSKIII N, N. "Géographie générale et géographie physique et économique" in Mémoires de la Société géographique de I'URSS. БАРАНСКИЙ Н. Н. "Страноведение и география физическая и экономическая в" Известия Всес. Геогр. о-ва. t. 78, n. 1, p. 9-24. 1946.

BARANSKIII N, N. Géographie générale et géographie physique et économique. Mémoires de la Société géographique de I'URSS. БАРАНСКИЙ Н. Н. "Страноведение и география физическая и экономическая в" Известия Всес. Геогр. о-ва. v. 78, n.1, p. 9-24, 1946.

BERG, L. S. Faciès, aspects géographiques et zones géographiques. Mémoires de la Société géographique de I'URSS. БЕРГ Л. С. “Фации, географические аспекты и географические зоны “ в Известия Всес. Геогр. о-ва. v. 77, n. 3, p. 162-164. 1945.

BORZOV, A. A. Tableaux géographiques de Russie. БОРЗОВ А. А. Картины по географии России. Moscou: Grossman et Knebel, 1908, n. 1, 192 p.

DIAKONOV, K. N.; MAMAï, I. I. Ecole de paysage de I'Université de Moscou: traditions, achèvements, perspectives. ДЬЯКОНОВ К. Н., МАМАЙ И. И. (ред.) Ландшафртная школа Московского университета : традиции, достижения, перспективы. Moscou: Roussaki, 1999, 200 р. verdadeiro objeto à geografia futura, dado que engloba a realidade natural e cultural, ligada não somente a um aspecto material da relação entre o homem e o meio, mas também ao seu aspecto espiritual. No entanto, é demasiado cedo ainda para falar de uma verdadeira mudança da concepção pitoresca na geografia póssoviética, porque a maioria das publicações continua a ser sempre limitada pelo quadro positivista e utilitarista da ciência da paisagem.

DOKOUTCHAEV, V. V. Rapport au Comité statistique de Transcaucasie à propos de l'évalution des sols en général et du Caucase, en particulier: zones pédologiques horizontales et verticales. ДОКУЧАЕВ В. В. Доклад професссора В.В. Докучаева Закавказскому Статистическому комитету об оценке земель вообще и - Закавказья, в особенности. Почвенные горизонтальные и вертикальные зоны. Tiflis, Tip. kants. Glavnonatch. grajd. tchasti na Kavkaze, 1899. 19 p.

DOKOUTCHAEV, V. V. Théorie des zones naturelles (ДОКУЧАЕВ В. В. Учение о зонах природы), Moscou: Geografguiz, 1948, 62 p.

DRONINE, N. M. Evolution de la conception du paysage dans la géographie physique russe et soviétique (ДРОНИН Н. М. Эволюция ландшафтной концепции в русской и советской физической географии), Moscou: GEOS, 1999, 232 р.

GUIERASSIMOV, I. P. Géographie constructive: buts, méthodes, résultats. Mémoires de la Société Géographique de l'URSS (ГЕРАСИМОВ И. П. “Конструктивная география: цели, методы, результаты “в Известия Всесоюзного Географического общества), v. 98, n. 5, р. 389-403, 1966. (en russe).

GUIERASSIMOV, I. P. Homme, société et environnement. Moscou: Editions du Progrès, 1975, 479 p.

GUIERASSIMOV, I. P. Le rôle de la géographie dans la construction socialiste en URSS et les tendances actuelles de son évolution. Essais de géographie. Moscou: Académie des sciences de l'URSS, 1956, p. 7 et suiv.

ISSATCHENKO, A. G. Science du paysage appliquée (ИСАЧЕНКО А. Г. Прикладное ландшафтоведение), Leningrad: ed.Leningradskogo Universiteta, 1976. 1ère partie. 149 p.

KAGANSKIII, V. L.; RODOMAN B. B. Paysage et culture. Numéro spécial de revue Science de culture: Bilans et perspectives (КАГАНСКИЙ В. Л., РОДОМАН Б. Б. Ладшафт и куР"ьтура, "Науки о куТ ьтуре: итоги и перспективы"), Moscou: Bibliothèque d'Etat de Russie, n. 3, 88 p., 1995.

KALOUTSKOV, V. N.; IVANOVA A. A.; DAVIDOVA I. A. et al. Paysage culturel du Nord Russe (КАЛУЦКОВ В. Н., ИВАНОВА А. А., ДАВЫДОВА Ю. А. Культурный ландшафт Русского Севера). Moscou: ed. FMBK, 1998. 136 p. 
FROLOVA, M. A paisagem dos geografos russos: a evolução do olhar geografico entre o século XIX e XX

KRASNOPOLSKIII A, V. Géographes de notre pays (1917-1992). Bibliographie (КРАСНОПОЛЬСКИЙ А. В. Отечественные географы (1917-1992). Библиографический справочник), Saint-Pétersbourg, 1995. 3 v., t. 3, 541 p.

KRASNOV, A. N. Fondements de la Géographie générale (КРАСНОВ Андрей Н. Основы землеведения), Kharkov, 1895-1898, n. 1-4.

NIKOLAIIEV, V. A. Chemin de V.V. Dokoutchaïev à la synthèse paysagère. Mémoires de l'Université de Moscou (НИКОЛАЕВ В. А. " Путь В.В. Докучаева к ландшафтному синтезу " в Вест. Моск. Ун-та), Moscou, MGu, série 5, 1996, n. 6, p. 3-8.

ORAIN, O. La géographie russe (1845-1917) à l'ombre et à la lumière de l'historiographie soviétique. L'Espace géographique, 3, p. 217-232. 1996.

PARROCHIA, D. Des réseaux trophiques aux écosystèmes. La maîtrise du milieu (textes réunis par Pascal ACOT), Paris-Lyon: VRIN-Institut Interdisciplinaire d'Etudes Epistémologiques, 1994, p.79-99.

RETEİOU, A. I. Facteurs et formes de l'organisation de l'espace de surface terrestre. Question de la Géographie. Recherche systémique de la nature ( РЕТЕЮM А. Ю. "О факторах и формах упорядоченности пространства оболочки Земли “ в Вопросы географии. Системные исследования природы), Moscou: Misl, 1977. t. 104, p.84-95.

RETEIIOU, A. I.; SIEREBRIANNYÏ L. R. La géographie dans le système des sciences de la terre. Bilans scientifiques et techniques: questions théoriques et générales de la géographie (РЕТЕЮМ А. Ю., СЕРЕБРЯННЫЙ Л. Р. “География в системе наук о Земле "в Научные и технические итоги : теоретические и общие вопросы географии), 1985, Moscou, VINITI. t. IV, $206 \mathrm{p}$.

ROUGERIE, G.; BEROUTCHACHVILI N. Geosistmas et paysages. Bilans et méthodes. Paris: Armand Colin, 1991, $302 \mathrm{p}$.
SAOUCHKINE, I. G. Paysage culturel. Questions de Géographie (САУШКИН Ю. Г. "Культурный ландшафрт “ в : Вопросы географии), n. 1, p. 97-106. 1946.

SEMIONOV-TIAN-CHANSKIII P. P. Géographie générale de l'Asie (rédaction, traduction et compléments de l'ouvrage de $\mathrm{C}$. Ritter) (СЕМЕНОВ-ТЯНь-ШАНСКИЙ Петр П. Землеведение Азии (Редакция, перевод и дополнения труда К. Риттера), Saint-Péterbourg, 1863-1885, 5 parties.

SOTCHAVA, V. P. La science structuro-dynamique du paysage et problèmes géographiques de l'avenir. Rapports de l'Institut de Géographie de Sibérie et d'Extrême-Orient (COYABA В. П. " Структурно-динамическое ландшафтоведение и географические проблемы будущего “в : Докл. Ин-та геогр. Сибири и Дальн. Востока), п. 16, р. 18-31. 1967.

COLLECTIF. Structure, fonctionnement, évolution des paysages naturels et anthropogènes (thèses du Xe congrès de paysage) (Структура, фрункцианирование и эволюция природных и антропогенных ландшафтов (тезисы X ландшафтной конференции), Moscou-Saint-Pétersbourg, ed. RGO.

VALEBNYII, V. V. et al. Paysage culturel: problèmes théoriques et méthodes de recherche (ВАЛЕБНЫЙ В. В., "ИВАНОВА А. А., КАГАНСКИЙ В." Л. Культурный ландшафт: вопросы теории и методологии исследования), Moscou-Smolensk, ed. SGU, 1998, 101 p.

VALEBNYI, V. V. Naturalisme scientifique et naissance de la science du paysage. Paysage culturel: problèmes théoriques et méthodes de recherches (ВАЛЕБНЫЙ В. В. " Научый натурализм и становление ландшафтоведения “ в Культурный ландшафт: вопросы теории и методологии исследования), Moscou-Smolensk, ed. SGU, 1998, p.14-25. 